\title{
Film
}

\section{LIGHT AND SHADOW AS INSTRUMENTS OF LITERARY AND VISUAL METAPHOR IN LIVIU REBREANU'S THE FOREST OF THE HANGED}

\author{
Carmen DOMINTE \\ National University of Music Bucharest \\ e-mail: carmendominte2@gmail.com
}

\begin{abstract}
Starting from their basic role as elements of literary, cinematographic and theatrical description, light and shadow develop a close relation in all these three arts. They exceed their primary purpose and become involved in the process of narrating the events and setting the mise-en-scène. Even more, they are also engaged in changing the atmosphere, visualizing the images, modifying the reader's or viewer's attention, increasing or diminishing the dramatic intensity, conferring dynamic effect, accumulating meaning and revealing symbolic, philosophical, psychological and metaphysical significance to literary, cinematographic and theatrical artworks. Transferred from literature to cinematography and theatre, light and shadow have to adjust their means of expression so that to correspond to the specificity of each art. Taking after the techniques in the art of drawing, naming the tree-dimension perspective and chiaroscuro, light and shadow bring new aesthetic values to theatre and cinematography. Regarded as instruments of creating literary and visual metaphors, light and shadow highly influence the perception of the images outlined by them. The study aims to take into discussion the manner in which light and shadow may be employed as instruments of creating literary as well as visual metaphors. At the same time, it analyses the transposition of a metaphor generated by light and shadow from literature to cinematography and theatre as in Liviu Rebreanu's "The Forest of the Hanged".
\end{abstract}

Keywords: light and shadow; metaphor; literature; cinematography; theatre;

\section{General Reflections upon the Relation between Light and Shadow in Literature, Cinematography and Theatre}

The employment of light as well as of shadow as dramatic elements emerges from the subjective and objective effects that may be identified not only in a literary but also in a cinematographic and theatrical works of art. Generally speaking, the objective effects consist of the changes that reshape the physical appearance of an object providing new connotations. The subjective effects aim to modify the receiver's perception upon the object in 
question, making him or her aware of all these changes. Pointing to the meaning or function(s) of light in a literary text, film or stage performance also triggers the necessity to tackle the relation established between light and shadow or darkness. In a narrative text, the description of light is usually included in passages that set the scene or accompany the action. It functions as an external element. Sometimes it is also used in characters' introspections, highlighting their particular thoughts or the flow of their consciousness and, this time, its function turns into an internal one. Transposed into a cinematographic representation or a theatrical performance light as well as shadow becomes a more dynamic element.

From Plato's allegory of the cave to Christian typology and further on to the techniques of literary outstripping and foreshadowing, light and/ or shadow have played an important part in directing reader's interest towards future narrative development ${ }^{1}$. Most of times, the employment of light or shadow in a literary text aims to double, to distort or, at least, to provide new dimensions to places, objects, scenery, characters they spot on. Each time a literary text includes references to light and/ or shadow it sets a visual miseen-scène of that particular descriptive tableau which makes it similar to paintings ${ }^{2}$. In other words, the literary light and/ or shadow set one of the basic structures of narrative imagery, the fictional space. The reader needs to depict the images that the literary text is providing following the author's selection of words and phrases in order to reproduce the whole tableau. These images $^{3}$ become visible during the act of reading. (Blanchot, 2007: 34)

The relation between light and shadow in a literary text functions both poetically and narratologically aiming to reveal dynamic effects as well as dramatic intensity that particular literary images consist of. Far from being just descriptive, the light or the shadow or both, most of times, cast the emotional and the psychological states of the characters, sometimes interfering in the narrative suggesting actions, events that may come or possible flows of characters' wishes, thoughts or dreams. Sometimes light and/ or shadow may play the part of one or several characters as in Mircea Eliade's Domnișoara Christinal Miss Christina or in Charles Dickens' A Christmas Carol. Other times, they may suggest the mere presence of this

\footnotetext{
${ }^{1}$ The traditional connotations of light and shadow are those of good and evil, life and death, imagination and reality leading to further associations in terms of morality, knowledge, science, progress and so on.

${ }^{2}$ In this line of thinking, John Ruskin, referring to modern painting, argues that shadows are in reality the most conspicuous thing in a landscape next to the highest lights. Thanks to the use of light and shadow in a painting, all forms could be not only understood but also explained by their agency. (Ruskin, 2005: 173-175)

${ }^{3}$ According to Maurice Blanchot the contact between the reader and the author is based on these images, either poetic or narrative, contained by the literary text and meant to fascinate the reader. (Balnchot, 2007: 35)
} 
type of characters as in Ion Luca Caragiale's La Hanul lui Mânjoalăl At Mânjoală's Inn: "There was some light in madam Mânjoală's room, and shadows move lively on the curtain". (Caragiale, 1981: 201) The same employment of shadow can be identified also in "Edgar Allan Poe's William Wilson: "Death approaches and the shadow which foreruns him has thrown a softening influence over my spirit." (Poe, 1951: 351) There are also situations when light and/ or shadow may even impersonate these characters as if having substance, but, at the same time, leaving behind a huge uncertainty over the real or unreal and fantastic or imaginary nature of these protagonists as in Liviu Rebreanu's Adam și Eval Adam and Eve: „Late, when gazing at the misterious reflections of the water's shining, he seems to recognize, raising from the waves, the real Isit, white and smiling." (Rebreanu, 1989: 69) This kind of narrative texts usually invites the reader to extend his or her literary approach to a more philosophical or religious dimension which reveals new other aspects to the basic narrative one as in Virginia Woolf's Jacob's Room: "In any case life is but a procession of shadows, and God knows why it is that we embrace them so eagerly, and see them depart with such anguish, being shadows." (Woolf, 1971: 70).

The literary texts that employ light and/ or shadow imagery accumulate meaning if not symbolic or metaphoric, at least visual or narrative. Moreover, placing a descriptive passage containing references to light or/ and shadow within a literary text not only intensifies the tension of the narrative but also extends the area of interpretations concerning all the other elements belonging to the very passage. In doing so, the employment of light usually in close relation to shadow facilitates the outline of literary metaphors. Depicted from a narrative text they become visual in the reader's eyes. It is the first step towards the act of visualizing literary images ${ }^{4}$. It is also the core element that connects literature with other visual arts such as cinematography or theatre. Whatever the art is, the visual metaphors exceed the basic denotative meaning and permit the accumulation of other inherent significations that may lead to a better understanding of the artwork.

Although in literature light and shadow usually play a secondary role, in cinematography they become very important elements of cinematic or theatrical narration. Especially light is considered a major factor that can radically change the entire image, frame by frame. Besides the fact that light makes any object, person or setting visible, it also provides new dimensions to the image which thus receives new dramatic values. Moreover, it controls the effect so that it may be reflected to the stage or screen in the most

\footnotetext{
${ }^{4}$ Further on, new connotations could be added to the basic image enriching it with symbolic, philosophical psychological, spiritual, religious meanings.
} 
efficient manner ${ }^{5}$. In fact, cinema and even theatre makes use of the lighting techniques taken from painting art but adapting them to the new environment so that they could function as specific instruments.

First it was the three-dimensionality determined by light and evaluated by Masaccio as the major technique of generating visual perspective. Then light became useful for supporting the effect of depth mainly in Tintoretto's paintings such as The Final Supper where it focuses on the persons placed around the table and effuses out from the window generating a dramatic effect. The employment of light-shadow relationship was also preferred by Caravaggio for creating sharp contrasts ${ }^{6}$ aiming to increase the importance of a character or an object by taking out the figure from the dark shadows and illuminating it with intense light. (Krausse, 2005: 36) Using the relation between light and shadow in such a way became a technique, called tenebrism ${ }^{7}$, from the Italian term tenebroso, and it was meant to help creating a very dramatic effect by using violent contrasts of light and shadow in a pronounced dark environment. Although the technique is preferred mainly by the seventeenth century painters, Georges de la Tour, Artemisia Gentileschi Francisco Ribalta, Jusepe de Ribera, Rembrandt and others, it was also used before by painters among whom there could be mentioned Tintoretto or El Greco (Buser, 2006: 88-90). Taking from Caravaggio, Georges de la Tour, for example, increased the mysterious atmosphere by employing only the light of a single candle as it may be observe in his painting The Birth. The very technique was further developed by Rembrandt who preferred to emphasize the emotional effect as well as the depth of the image mainly through creating transparent dark effects, which are specific for his paintings ${ }^{8}$ (Krausse, 2005: 42). When employed by other arts, such as cinematography and theatre, three-dimensionality as well as tenebrism becomes useful for creating an environment to tell a story. Light and shadow may determine specific areas of interest in a cinematic frame or on stage leading the viewer's attention towards what is intended to be noticed or, on the contrary, to be

\footnotetext{
${ }^{5}$ The perception of an image depends on the environment it contains, on the modifications towards light and shadow. A bright light or a diminished one highly influences human emotions. It is the relations rather than the individual elements of a painting that are significant to the human eye. (Gombrich, 2000:49)

${ }^{6}$ Considered a particular type of chiaroscuro, Caravaggio's sharp contrasts between light and shadow is also known as the style of the basement. (Krausse, 2005: 35)

${ }^{7}$ A seventeenth century painting technique, tenebrism was used for emphasizing the contrast of light and shadow so strong that the objects placed in a completely dark environment may seem closer and bigger because of the abruptly illuminating effect on them. (Buser, 2006: 87-88)

${ }^{8}$ Opposed to the light employed by Caravaggio, Rembrandt's light is not meant to reveal the details of the figures but to spring out of them. As a poor enlightenment this type of light seems to be emitted by the figures.
} 
hidden. An insignificant detail may modify the whole perception of an image only because it was so intensely enlightened as to provide more dramatic tension to the scene.

Similar to literature, in both cases, of cinematography and of theatre, light and shadow give meaning to any image. In the realm of expressionistic staging, based on directional light ${ }^{9}$, shadow is as important as light. For the theatre pioneers, Adolphe Appia and David Blasco, the manipulation of light and shadow represented a true means of expressing ideas. (Brown, 2008: 16). The effects ${ }^{10}$ determined by the use of light and shadow as dramatic elements are meant to activate the space as well as the time. Taking after painting techniques, the use of light and shadow in cinematography and theatre aims to provide depth to the composition. At the same time and taking after literary techniques, light and shadow are employed as instruments of narration. Thus, from a spatial perspective, the light coming from the front sharpens the features of the object or person it spots on while the light at the back generates a silhouette. The light coming from bottom, top or sides generate particular emotional occasions through creating different shadow forms ${ }^{11}$ (Butler, 2005: 33-35). Likewise, from the perspective of time, the density of light increases or decreases for providing natural effects which, on their turn, generate dynamism to the life on stage or in film. Most of times, these effects are in close connection to specific psychological moments revealing unexpected aspects of the evolution of certain characters. Furthermore, they are meant to support the intrinsic meaning of each scene. The whole mise-en-scène, either in film or in theatre, is always in close relation with the basic six elements involved in any type of staging: set, lighting, costumes, hair, makeup and action. At this point, lighting may be regarded as both a narration and metaphorical instrument. Viewed as an instrument capable to shape the stage, lighting makes use not only of threedimension perspective but also of chiaroscuro as basic techniques in order to represent appearances. Based on the constancy of light's behaviour on stage, the space is in constant modification as the light's edges are slicing the stage,

\footnotetext{
${ }^{9}$ Directional light, as it is called in the aforementioned fields, dates back to the French chemist Lavoisier who, in 1781, introduced movable reflectors to be added to oil lantern on stage. After using gaslight and limelight, the lighting control was based on plano-convex lenses and spherical reflectors. The forerunner of most of the modern lighting was the incandescent spotlight invented by the electrician Louis Hartmann. (Brown, 2008: 17)

${ }^{10}$ These effects may be either objective, when the appearance of the object or person is changed, but there are no important modifications in the viewer's perception of the image, or subjective, when the level of light highly influences the viewer's perception.

${ }^{11}$ The artificial lighting is mainly employed to better reflect the whole environment, but it may also focus on certain areas, most of times containing objects or characters, aiming to guide the viewer's attention towards particular details that emphasize the essence of the image. (Krausse, 2005: 87-88)
} 
the sight-lines are varying predictably generating different shadow shapes. Thus perspective allows the staging of the so-called geometry of light. Nonetheless, chiaroscuro and tenebrism also model the figures in light and shade is a manner similar to painting (Herrstrom, 2017: 82).

Regarded as basic mise-en-scène elements, light and shadow become instruments of narration not only in literature but also in cinematography and theatre. Besides their main narrative function they also exert the function of creating metaphors either literary or cinematographic and theatrical. Taking the literary text as a starting point, the employment of light as well as of shadow is always adjusting its means of expression according to the art it belongs to. Each time, either in a literary environment or in a cinematographic or theatrical one, light and/ or shadow always affect the narration of events by accumulating new meanings. Moreover, they confer visibility to hidden details or emphasize others in order to guide the reader's and the viewer's attention towards the important points of interest, aiming for a more expressive atmosphere and a better understanding of a particular scene or of the whole artwork. By their literary, cinematographic and theatrical focalization, light and shadow may predict or change the perspective upon a character, an event, an atmosphere and so on. As instruments of creating literary and visual metaphor, light in relation with shadow exceeds its narrative and descriptive purpose towards symbolic, metaphysical, philosophical, psychological and other significations.

\section{The Metaphor: from Literary to Visual}

In a literary environment, light and/ or shadow may play primary or secondary roles. Their functions usually pass from mere descriptive to narrative. They may also become engaged in accumulating meaning, in conferring symbolic, metaphysical, psychological or philosophical significations and, sometimes, in predicting or changing the perspective over an image. Setting the mise-en-scène of a literary scene, the use of light and/ shadow permits the outline of certain metaphors that could add new literary nuances as in Liviu Rebreanu's Pădurea spânzuraților/ The Forest of the Hanged. In fact, the novel may be regarded as being dominated by light and shadow as the two major poles that delimitates the external fictional space as well as the main character's, Apostol Bologa, inner psychological struggle. During the whole novel light reflects the moments of crisis ${ }^{12}$. From the very beginning light and shadow are related to the image of war and trauma as perceived by human consciousness, predicting the future events. According to the protagonist's words, darkness best represents the gloomy atmosphere

\footnotetext{
12 According to George Călinescu, the novel should be regarded as the analysis of the psychological crisis that is experienced by an ordinary human soul engaged in a personal fight with a dramatic life. (Călinescu, 1985: 733)
} 
that covers everything: "Such darkness, God, such darkness came over Earth." (Rebreanu, 1966: 23).

Either it is natural or artificial light is always in sharp contrast with shadow symbolically suggesting a psychological confrontation between the main character's feelings, emotions or thoughts. A good example in this sense is the presence of the spotlight. Focusing on certain areas, it reveals particular details about the soldiers' positions. Based on this fact, it is decided to be destroyed ${ }^{13}$. Regarded from a symbolic perspective, the intensive light is focusing on the protagonist's consciousness unveiling his psychological struggle between his belief in duty and his belief in a new world which he desperately tries to reject. (Lăzărescu, 1983: 148-149). That explains the paradox between the main character's decision to eliminate the spotlight and his reaction on his own deed. Apostol Bologa questions himself as if questioning someone else and ends up in blaming himself for what he has done. The light murdered in a violent act ceases to be a concrete, real light and becomes the tormenting light that haunts the protagonist's thoughts. From this moment on light is more and more replaced by darkness. Its presence seems to diminish as in the opening of the second part of the novel where it is "a small, foggy and troubled spot of light" (Rebreanu, 1966: 113). Even more, right when Apostol Bologa is detained by the army, light starts to fade and, in the end, it disappears into the flood of darkness. The fourth part of the narrative is dominated by darkness leading the protagonist towards death but, as the final moment approaches, light comes again to illuminate his soul. As he is taken to the place of execution, Apostol Bologa raises his eye to the starless sky and gazes at the light of the rising sun. From this point of view, the protagonist's death marks not only the end of his psychological struggle but also his exit from darkness into the divine light.

In general, the visual feature of the metaphors allows their employment as elements of literary, cinematographic or theatrical mise-en-scène. At the same time, the same feature makes possible the transposition of these metaphors from one art to another adjusting the material of artistic representation. From the literary text to the cinematographic frames or theatrical performances, these visual metaphors have been constantly modified according to the technical possibilities of each particular art for a better representation. In this respect, light and/ or shadow have adapted their means of expression from literary to visual ${ }^{14}$. In the process of adaptation of a

\footnotetext{
${ }^{13}$ Based on its further psychological implications, the whole event is highly amplified and, thus, an act of war is transposed into a metaphysical symbol that stands for the extinction of light itself. (Protopopescu, 1978: 84)

14 There is a visual characteristic that could be usually identified in any literary image or metaphor but, opposed to the literary environment where such images or metaphors are
} 
literary text into a film or a staged performance, the employment of light and shadow as instruments of creating metaphors has been negotiated in order to transpose each metaphorical item from one artistic environment to another but, at the same time, to generate new opportunities of expression.

As previously analysed the employment of light and shadow in a literary text is meant to set an adequate environment for the events to come, in this case the war, or to focus on the moments of crises, when the background necessarily corresponds to the characters' psychological states for emphasizing their inner struggles or, on the contrary, it contrasts with the heroes' emotions in order to make them more evident. Having the same purposes, the use of light and shadow either in a cinematographic or theatrical environment is involved in drawing the pictures that illustrate a specific background as well as a specific detail that may contribute to the dramatic representation of the scenes. These pictures have engaged light and/ or shadow on the basis of the following two main painting techniques, the three-dimension perspective and chiaroscuro ${ }^{15}$. Making use of these techniques, the cinematographic and theatrical representations employed light and/ or shadow differently.

The first example is the homonymous film adaptation directed by Liviu Ciulei. Filmed in 1964 and released in 1965, this adaptation is in white and black thus emphasising even more the dramatic effect of each frame. In order to create not only a dark image of the war but also to anticipate the future tragic events, the general perspective is supported by low density lighting and light-shadow juxtaposition. Besides the pessimist and suffocating atmosphere that was

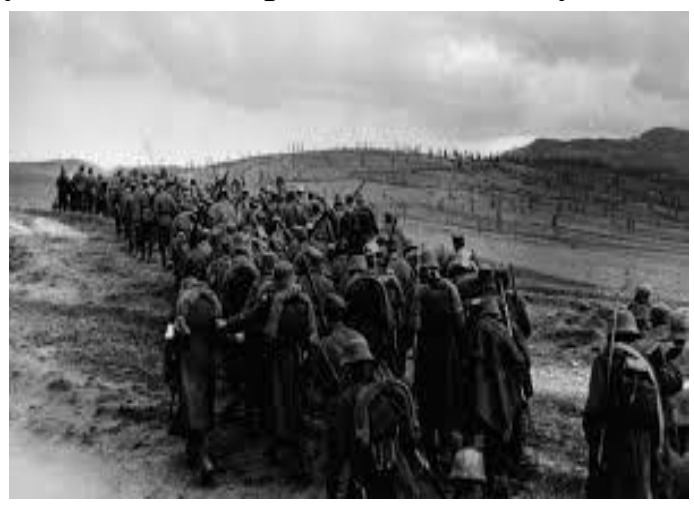

Figure 1 Perspective generated through soft lighting which dominates the whole general plan, the shadows of the huge group of people are dense in the front and fades away in the distance as it may be noticed in the Figure 1. Here the sharp line of the horizon is intersected by the thick line of people that becomes thinner till it disappears in the distance.

The same type of lightening can be identified in an interior shot as observed in the Figure 2. Here the effect of depth is supported by the light

revealed by imagination in a cinematographic or theatrical environment it mainly defines the means of artistic expression.

${ }^{15}$ These two techniques are not the only ones usually employed in film or stage productions. 


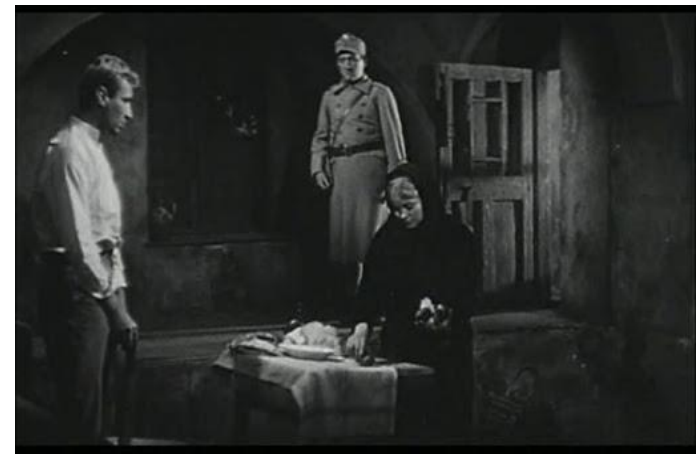

Figure 2 Perspective

that focuses on the table as well as on the protagonist standing near the table. The lighting is clearing out in the background. The main character is enlightened through a soft light coming from the right side and a front light but with lower density. There is another light

that comes from the back right through the door and also focuses on the protagonist ${ }^{16}$. Such a focalisation is meant to contour the hero and to separate him from the background mainly through the use of light that provides depth to the character. By separating the subject from the whole environment it is intended to draw more attention on the main character. The importance of the protagonist is highlighted by his standing posture, occupying the entire left extreme of the picture but mainly by the place he is positioned: forefront left ${ }^{17}$.

Both these examples exemplify the manner in which the human figures placed within a picture, either in an exterior or interior frame shot, can gain three-dimension perspective through the use of soft light adjustment.

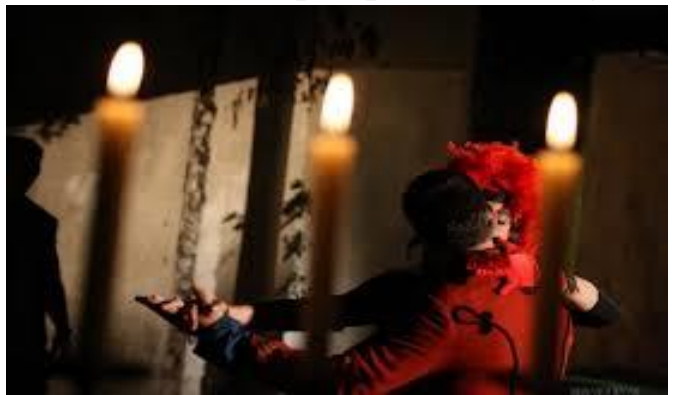

Figure 3 ChIAROSCURO

Light is also engaged in creating the well-known chiaroscuro. The sharp contrast between intense light and intense shadow sets a new way of interpreting the importance of the figures and their detachment from the background as in the following examples belonging to another film adaptation of the same novel but entitled Apostolul Bologal The Apostle Bologa, directed by Dominic Dembinski and released in 2018. In this case, light is involved in creating the volume through light and shadow contrasts provided by the enlightenment coming from the back or/ and sides. The intense light coming from the back as well from the right side is in high contrast with the figures placed in the middle separating them from the whole picture and thus dramatizing the atmosphere, as it may be seen in Figure 3. As opposed to the previous case,

\footnotetext{
16 The scene analyzed in Figure 2 represents a good example for the manner in which the display of the three directional type lighting may employ light for depth effects.

${ }^{17}$ Such a position of the extreme importance since the reading of a picture starts from here.
} 
the one shown in Figure 2, when the light focalizes on the protagonist leaving the background in the shadow, this time, light covers the background and leaves the two characters in the shadow so that their features become difficult to be distinguished.

The dramatic effects turn to be more intense when the light source is diminished. Thus the light of one or two candles or a lamp could create a mysterious atmosphere, as in Figure 4 or in Figure 5. Both cases make use of practical lighting ${ }^{18}$ provided by the lamp as well as by the candles in order to give off subtle lighting

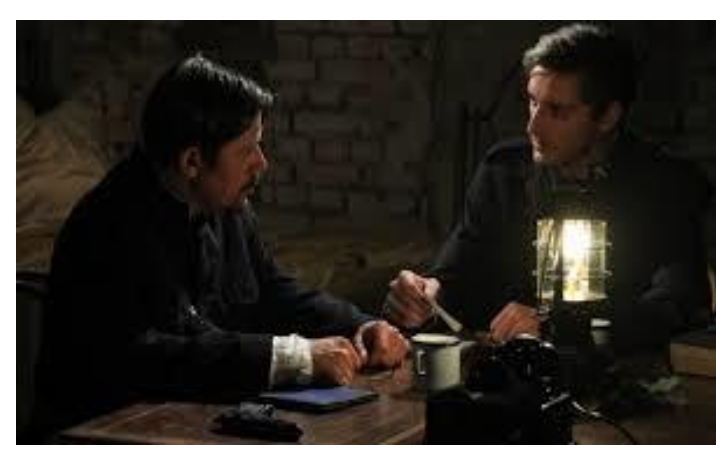

FIGURE 4 CHIAROSCURO for the characters in the scenes. Although there are extra source of lighting, the lamp and the Figure 3 Chiaroscuro candles represent the key light, meaning the main source of light registered most prominently in the frame, with low density for both frames. The light provided by the lamp contours the arms, the faces and the hair of the two subjects. On the other hand, candles have a different function.

Because of their forefront position as well as of their enlarged size they become the main subjects, attracting all the attention, as in the paintings of Caravaggio or Georges de la Tour. The candles' lights highly contrast with the other areas which are completely dark except the secondary plan which contains the two characters whose dance is obstructed by the position of the candles, as if being of less importance. The side light that fills

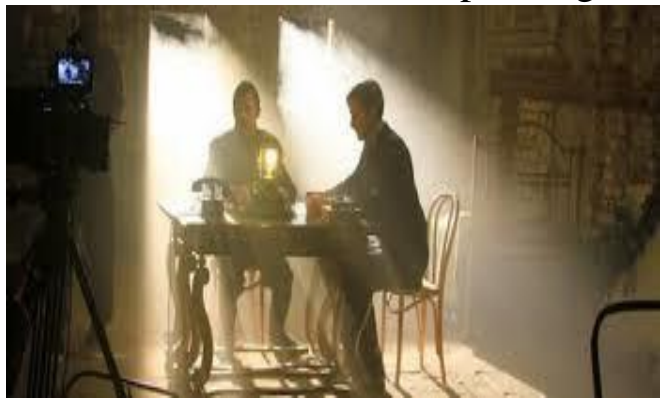

Figure 5 Chiaroscuro in the frame also contours a silhouette that Figure 6 - Perspectivel Chiaroscuro fades away in the background.

\footnotetext{
18 In the art of cinematography a proper lighting technique is essential. Usually, in filmmaking a single technique is composed of several other lighting techniques. It is the case of practical lighting too. Since the light coming from a single lamp or few candles is not strong enough to light up a small area or a subject/ object, a hidden, supplementary source of light is used. Sometimes there are inserted dimmers in the lamps so the light intensity may be adjusted appropriately.
} 


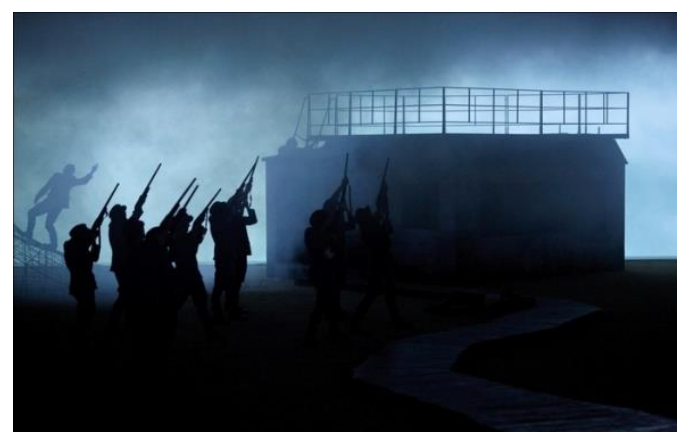

Light and shadow may be employed for increasing a dramatic effect of a scene not only in cinematography but also in theatre. Combing perspective with chiaroscuro, the stage effects accentuate their dramatic intensity as in the homonymous play directed by Radu Afrim ${ }^{19}$. The

Figure 6 Perspective/ Chiaroscuro literary fragment illustrating the scene of shooting and murdering the spotlight was staged by making use of the powerful effects that light in association with shadow may provide as it can be observed in Figure 6. Most of the subjects are placed in complete shadow so that their silhouettes to highly contrast with the environment. It is impossible to distinguish any other features except the human bodies and the rifles, the key elements of scene. At the same time they occupy the forefront left position which is the most important area in a picture or painting. Perspective is suggested by the path that narrows in the distance, by the building whose

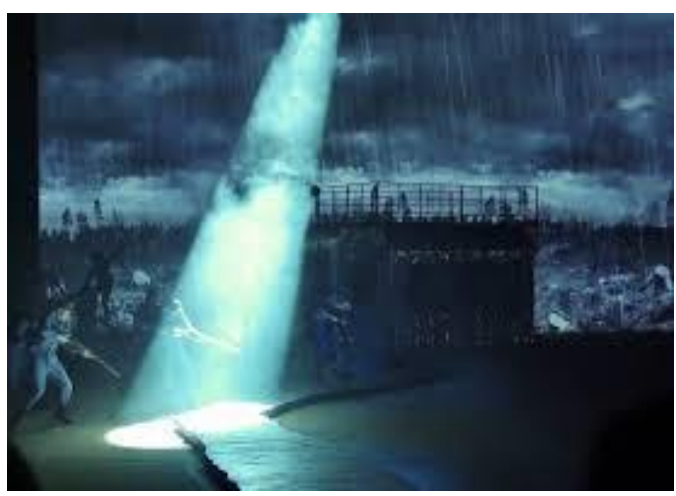

Figure 7 Perspective/ Chiaroscuro dimension was reduced, by the small human figure in the back and by the foggy light that diffuses from the back to the front of stage. What strikes here is the very sharp contrast of chiaroscuro based on the general light. In order to increase even more the dramatic effects of the same scene, the general light is concentrated in the spotted light placed in the most significant position as seen in Figure 7. The same elements create perspective but the contrast is softer.

Combing all the elements that provided perspective as well as chiaroscuro and insisting on the sharp contrast based on the employment of light and shadow it may become possible to generate a great impact on the whole picture of the same scene. As noticed in Figure 8, two types of light intersect. Light that comes from above focuses on the subjects while the shadow increases the dramatic effect by contrast. Light that comes from the

19 The first performance of the play was in 2018 on the stage of the National Theatre in Bucharest. 


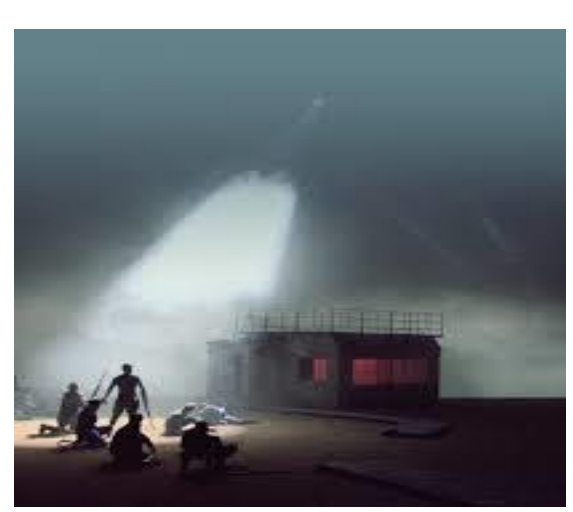

Figure 8 Perspective/ Chiaroscuro

back is soft, foggy and of low intensity. Thus, by combing the intense light of the spot with soft light from the back there could be created the transparent-dark effect ${ }^{20}$ that covers few of the subjects and creates depth of the picture which thus accumulates emotional effects. The intensity of the light fades from the spot to the sides, leaving the human figures in the dark.

Besides the purpose of making the object and subject visible, light in connection with shadow dominates the place. It is no longer the light employed for perspective as in Figure 1, neither the light used for generating contrasting effect based on chiaroscuro meant to attract attention or to contour the subjects and the objects as in Figure 4 and Figure 5 it is a combination of lights in relations with shadows. Similar to film, such combination of lights is meant not only to increase the dramatic effect of a scene but also create visual metaphors. Avoiding general lighting, the dramatic effects obtained through such combination of lights carry the dramatic tension to a climax. The visibility of the objects as well as the features of the subjects comes on secondary level of importance.

The meaning created by lighting as a mise-en-scène may reveal not only the dramatic or the tragic and gloomy aspects of a specific place but also the metaphysical aspects meant to illuminate a place of uncertain conditions. On the psychological level, the meaning unveiled by visual metaphors is to give an insight into the protagonist's mind and to make visible his inner struggle between duty and desire as well as his perception of a world filled with war. The use of light-shadow relations is meant to reveal the spiritual and metaphysical rather than the material and real dimension, increasing the emotional effect.

Exceeding their basic narrative purpose, whenever employed as instruments of creating literary and visual metaphors, light and/ or shadow become capable of a much more impact on the reader and viewer ${ }^{21}$. At the same time a metaphor is more suggestive that a narrative, allowing the reader

\footnotetext{
20 The transparent-dark effect was masterly created by Rembrandt in his paintings. The employment of light was meant to create a poor enlightenment of the scene and thus emphasizing the depth. Such light softly concentrates on the subjects and falls into dark shades that surround the image. It could also be easily recognized as the phosphorescence light that occurs around the faces of the subjects adding new connotations to the painting.

${ }^{21}$ As expected, the visual impact is always stronger than the impact generated by a literary text, in spite of the gloomy and horror passages included in descriptions or narratives.
} 
or the viewer to identify additional meanings and aspects to the basic ones. In all these cases, the extra dark in combination with the extra light tones and nuances, since there are other colours involved, contributes to the specific atmosphere that brings the mise-en-scène into the foreground and confers poetic qualifications to the world it has created.

\section{Final Remarks}

Starting from a literary manner of producing metaphors through the use of light and shadow, the cinematographic and the theatrical manner proved to be as creative as the former. The visual feature of such metaphors represents the core element of all these three arts that makes possible the transfer of the aesthetic connotations of the literary metaphor into a cinematic and theatrical environment adding further aspects. Taking after the use of light and shadow within the art of drawing, the employment of light in relation with shadow has extended its possibilities in other visual arts. Thus the light effects are basically meant to consolidate the stage as well as the scene through creative solutions but they also may set a specific atmosphere, change the appearance of the objects and the subjects they spot on, modify the appearance not only of the items they focalize, but also the action and the events, accumulating meaning and providing dramatic intensity and revealing symbolic, metaphysical, philosophical and psychological significance. The contribution of light and shadow relationship that started with Caravaggio and culminated with Rembrandt has been hired, adapted and developed by other visual arts. According to the means of artistic representation specific to each art, in this case, literature, cinematography and theatre, light and/ or shadow can be employed as instruments used for creating the mise-en-scène that further may function as a basis for setting the scenes, narrating the events and creating powerful literary as well as visual metaphors.

\section{References:}

Blanchot, M. (2007). Spațiul literar/ Literary Space, trans. by Irina Mavrodin. București: Editura Minerva.

Brown, B. (2008). Motion Picture and Video Lighting. Oxford: Focal Press.

Buser, T. (2006). Experiencing Art Around Us. Belmont: Thomson Wadsworth.

Butler, A. (2005). Film Studies. Harpenden, Hertfordshire: Pocket Essentials.

Caragiale, I.L. (1981). Nuvele, povestiri, amintiri, varial Short Stories, Tales, Memoires, Varia. București: Editura Minerva.

Călinescu, G. (1985) Istoria literaturii române de la origini până în prezent/ The History of Romanian Literature from the Beginnings to Present, București: Minerva. 
Gombrich, E H. (2000). Art and Illusion: A Study in the Psychology of Pictorial Representation. Princeton: Princeton University Press.

Herrstrom, D. (2017). Light as Experience and Imagination from Paleolithic to Roman Times. London: Fairleigh Dickinson University Press.

Krausse, A.C. (2005). The Story of Painting: From the Renaissance to the Present, Königswinter: Könemann.

Lăzărescu, G. (1983) Romanul de analiză pshihologică în literatura română interbelică/ The Novel of Psychological Analysis in the Interwar Romanian Literature, București: Minerva.

Poe, E.A. (1951). Great Tales and Poems of Edgar Allan Poe. New York: Washington Square Press.

Protopopescu, A. (1978). Romanul psihologic românescl The Romanian Psychological Novel, București: Editura Eminescu.

Rebreanu, L. (1989). Adam și Eva/ Adam and Eve. București: Editura Minerva.

Rebreanu, L. (1966). Pădurea spânzuraților/ The Forest of the Hanged. București: Editura pentru Literatură.

Ruskin, J. (2005). Modern Painters, volume 1. Whitefish: Kessinger Publishing.

Woolf, V. (1971). Jacob's Room. London: Hogarth.

\section{Online Resources:}

Figure 1 and Figure 2:

http://www.google.com/search?q=padurea+spanzuratilor+imagini\&tbm=isch\&sourc $\mathrm{e}=$ univ\&sa

Figure 3, Figure 4 and Figure 5:

http://www.google.com/search?q=filmul+apostol+bologa\&tbm=isch\&source=univ

$\underline{\mathrm{sc}=}$ X\&ved

Figure 6, Figure 7 and Figure 8:

http://www.google.com/search?q=padurea\%20spanzuratilor\%20imagini\&tbm=isch

\&tbs =rimg 